\title{
We need a stroke system
}

\author{
Gilberto KK Leung *, FHKAM (Surgery), LLM \\ Department of Surgery, The University of Hong Kong, Queen Mary Hospital, Pokfulam, Hong Kong
}

*Corresponding author: gilberto@hku.hk

Hong Kong Med J 2018;24:9-10

DOl: $10.12809 / \mathrm{hkmj} 175075$

Trauma and acute stroke services share common features of being time-dependent, high-stakes, resource-intensive, and multidisciplinary in nature; both call for a robust system of care. In Hong Kong, we established a trauma system some one and a half decades ago. ${ }^{1}$ There is no reason why we cannot and should not do the same for stroke if Hong Kong, for all its worth, is to proclaim itself a 'world-class city'. We need to build a stroke system.

\section{Unmet needs}

The fact that stroke will impose a considerable burden on our ageing population needs no elaboration. ${ }^{2}$ The introduction of intravenous thrombolysis (IVT) and mechanical thrombectomy (MT) has provided us with reliable tools to address these challenges-both IVT and MT are proven and clinically accessible treatments that can significantly improve patient outcomes. ${ }^{3}$ But while IVT is, arguably, fairly well established in Hong Kong, the provision of MT, as demonstrated by Tsang et $\mathrm{al}^{4}$ in this issue, remains uncoordinated, patchy, and inconsistent.

Mechanical thrombectomy involves the use of endovascular intervention within 6 hours of symptom onset. Its provision can be realised only if patients are directly admitted or secondarily transferred to a specialist unit in a timely manner. ${ }^{3}$ Although we have the expertise, it is presently spread across too many hospitals, few of which can individually sustain a full-fledged 24/7 stroke service. There is currently no designated stroke centre or sufficiently formalised referral network to ensure that patients will be treated at the right place and at the right time. Far too many patients are being denied these liferedefining therapies. Something needs to be done.

Merely having a few strategically placed stroke centres will not suffice. The singular solution is to adopt a territory-wide 'system approach' whereby prehospital diversion, secondary transferral arrangements, protocol-driven triage, and expeditious intervention can become the norm, as it is for trauma. ${ }^{5}$ Optimal stroke care also encompasses prevention, public education, rehabilitation, postdischarge social care, professional training, audit, and research. ${ }^{6}$ The presence of a formalised stroke system will serve to raise awareness, lend legitimacy, facilitate cultural change, and entice the injection and consolidation of resources for these purposes.
Without it, we will forever sit passively at the receiving end of an impending stroke tsunami, shouting complaints and drowning in our own complacency.

\section{Legal liabilities}

Scientific evidence and judicial outcomes suggest that IVT and MT will likely become not only medically accepted but also legally required standards of care under common law, and a failure to provide these treatments may well fulfil the burden of proof in medical negligence. ${ }^{7}$ Numerous IVT-related claims have already materialised overseas including, but not limited to, 46 in the United States by $2013 .{ }^{8}$ The majority of reported cases involved doctors' failure to treat, and hospitals were often found vicariously liable. In Australia, an inquest is currently underway into the deaths of two stroke patients at a hospital where both stroke interventionists were allowed to go on leave at the same time. ${ }^{9}$

It takes little imagination to contemplate the first related claim in Hong Kong should our situation remain unchanged. To defend it by saying that 'we do not yet have these services' would be untruthful because we do; they are just not properly organised. At present, depending on where one lives or develops a stroke, acute stroke care may be available all the time, during office hours only, or not at all. Although it is unrealistic to expect a comprehensive stroke service at every hospital, doctors can and do have the professional duty to refer. Few of us would question nowadays whether burn or head-injured patients should be transferred to a specialist unit. Stroke patients should be no exception. The question is about knowing where, when, and how.

Stroke claims are invariably expensive and demoralising. From a utilitarian standpoint, we only need a few successful claims to undermine any 'savings' gained through inaction, while damage to individual reputations and payouts through indemnity coverage will eventually be transferred to the rest of the professional community. Taxpayers will also want to see their money better spent. We must invest to save.

\section{Corporate responsibilities}

During the regionalisation of trauma services in Hong Kong, recommendations by external experts were accorded substantial weight and influence. 
We had unequivocal mandates from the highest authorities within the public sector that provided clear instructions and directions for change. A casevolume-orientated approach superseded the rigid, if not frigid, cluster-based thinking; five instead of seven trauma centres were designated in 2003. Collaboration with the ambulance services soon led to primary trauma diversion whereby patients are sent to the most appropriate centre instead of the nearest hospital. A clear sense of corporate responsibility and ownership was palpable. As a result, we now have a trauma system that is at least accountable if not respectable. Why don't we take advantage of these valuable experiences and attempt the same for stroke?

The situation for stroke is that professional groups are still expected to work things out among themselves, find solutions, bid for resources, and, should they fail, keep trying. Although this may well be administratively necessary or even sound, more decisive and incisive steering and driving will undoubtedly move things farther and quicker. In the United Kingdom, acute stroke services were regionalised in two metropolitan cities using different strategies. Better access to care was soon established in London, where a top-down approach was used, than in Greater Manchester that adopted a more bottom-up method. Clinical and cost outcomes were correspondingly different. ${ }^{10}$ The choice and decision is one for the wise. Meanwhile, what we need is a clearer and stronger declaration of the vision and mission to build another respectable and accountable system of care here in Hong Kong.

This is not to say that we should simply copy and paste. What works in other countries may not be applicable here. We must learn, adapt, and be pragmatic. Local lessons from trauma system implementation also taught us that perpetual reliance on good will alone would not sustain something as demanding as a trauma or stroke system; additional resources must be planned for and availed. The designation of a specialist centre is essentially an irremediable step of franchising that has to be done boldly and carefully, as subsequent de-designation can be a potential cause of stroke for some. (We ended up with more trauma centres than we need with no realistic prospect of rectification.) Plainly, we do not want a 90-minute prehospital time for stroke but neither do we need a stroke centre at every street corner. It is a delicate balance between access to care, the concentration of clinical experience, and cost-effectiveness. Similarly, the failure to establish a regional trauma registry was a monumental error that must not be repeated. ${ }^{11}$ It all comes down to having the will and power to evolve, a lot of common sense, and, of course, proportional and handsome funding.

Hong Kong is blessed with an abundance of medical talent as well as an efficient and arguably well-subsidised health care system. We do not need to re-invent the wheel or try to build Rome. We already have the experience and machinery for change. The needs are real, the liabilities foreseeable, and the responsibilities non-delegable. Instead of leaving our stroke patients to nature's course, there is much that we can and must do. The people of Hong Kong deserve better. Hong Kong deserves a stroke system.

\section{Declaration}

The author has disclosed no conflicts of interest.

\section{References}

1. Leung GK, Chang A, Cheung FC, et al. The first 5 years since trauma center designation in the Hong Kong Special Administrative Region, People's Republic of China. J Trauma 2011;70:1128-33.

2. Woo J, Ho SC, Goggins W, Chau PH, Lo SV. Stroke incidence and mortality trends in Hong Kong: implications for public health education efforts and health resource utilisation. Hong Kong Med J 2014;20(Suppl 3):S24-9.

3. Miller JB, Merck LH, Wira CR, et al. The advanced reperfusion era: implications for emergency systems of ischemic stroke care. Ann Emerg Med 2017;69:192-201.

4. Tsang AC, Yeung RW, Tse MM, Lee R, Lui WM. Emergency thrombectomy for acute ischaemic stroke: current evidence, international guidelines and local clinical practice. Hong Kong Med J 2018;24:73-80.

5. Whelan KR, Hamilton J, Peeling L, Graham B, Hunter G, Kelly ME. Importance of developing stroke systems of care to improve access to endovascular therapies. World Neurosurg 2016;88:678-80.

6. Lindsay P, Furie KL, Davis SM, Donnan GA, Norrving B. World Stroke Organization global stroke services guidelines and action plan. Int J Stroke 2014;9 Suppl A100:4-13.

7. Blyth CO, Dudley N. Litigation risks with the National Stroke Strategy. BMJ 2007;335 [Response to: Short R. UK government to spend $£ 105 \mathrm{~m}$ to improve stroke services. BMJ 2007;335:1231.] Available from: http://www.bmj.com/ content/335/7632/1231.2/rapid-responses. Accessed 26 Nov 2017.

8. Bhatt A, Safdar A, Chaudhari D, et al. Medicolegal considerations with intravenous tissue plasminogen activator in stroke: a systematic review. Stroke Res Treat 2013;2013:562564.

9. Crouch B. Royal Adelaide Hospital knew its stroke service was 'indefensible' time bomb but failed to address it before two patients died. The Advertiser 2017 June 16. Available from: http://www.adelaidenow.com.au/ news/south-australia/royal-adelaide-hospital-knew-itsstroke-service-was-indefensible-time-bomb-but-failedto-address-it-before-two-patients-died/news-story/ e0ecfeb7c359347fe461c8caaeca9bf6. Accessed 20 Dec 2017.

10. Fulop NJ, Ramsay AI, Perry C, et al. Explaining outcomes in major system change: a qualitative study of implementing centralised acute stroke services in two large metropolitan regions in England. Implement Sci 2016;11:80.

11. Leung GK. Trauma system in Hong Kong. Surg Pract 2010;14:38-43. 